\title{
(息)
}

Citation:

Rodrigues, S and Kaiseler, MH and Queirós, C and Pereira, MB (2017) Daily stress and coping among Emergency Response Officers: a case study. International Journal of Emergency Services, 6 (2). pp. 122-133. DOI: https://doi.org/10.1108/IJES-10-2016-0019

Link to Leeds Beckett Repository record:

https://eprints.leedsbeckett.ac.uk/id/eprint/3764/

Document Version:

Article (Accepted Version)

The aim of the Leeds Beckett Repository is to provide open access to our research, as required by funder policies and permitted by publishers and copyright law.

The Leeds Beckett repository holds a wide range of publications, each of which has been checked for copyright and the relevant embargo period has been applied by the Research Services team.

We operate on a standard take-down policy. If you are the author or publisher of an output and you would like it removed from the repository, please contact us and we will investigate on a case-by-case basis.

Each thesis in the repository has been cleared where necessary by the author for third party copyright. If you would like a thesis to be removed from the repository or believe there is an issue with copyright, please contact us on openaccess@leedsbeckett.ac.uk and we will investigate on a case-by-case basis. 


\section{Daily stress and coping among Emergency Response Officers: a case study}

\section{Abstract}

3 Purpose: Police in Europe are facing increased demands and diminished resources, and this is

4 particularly prominent among Emergency Response Officers (EROs) working in poorer

5 countries such as Portugal. Considering that daily stress and limited coping skills can result in

6 detrimental consequences for officers' health and society welfare, this study investigated stress

7 and coping among Portuguese EROs.

8 Design: EROs completed daily diaries over 11 working days. Each diary entry included an open-

9 ended stressor, coping section and a Likert-type scale to evaluate coping effectiveness. Data was 10 analyzed using inductive and deductive content analysis procedures. The frequency of stressors,

11 coping and coping effectiveness were calculated.

12 Findings: EROs reported facing more operational stressors, particularly public disorder

13 situations. However, gun situations were perceived as the most intense stressor. Emotion-focused

14 coping (i.e., peer support) was more used than problem-focused. Despite variation in coping

15 effectiveness in accordance to stressor experienced, longitudinal analysis suggests that PF coping 16 is more effective.

17 Research limitations/implications: Longitudinal methodologies should contemplate stress 18 appraisal and coping effectiveness in order to fully understand stress and coping. Future studies 19 should employ this methodology at a larger scale and over longer periods.

20 Practical implications: Intervention programs for EROs should be multidimensional, targeting 21 work conditions and resources, stress management, and coping effectiveness.

22 Originality/value: Findings provide strong recommendations for future research and applied 23 implications for stress prevention and effective coping interventions. 
24 Keywords: stress, coping, diary methodology, police forces

25

26

27

28

29

30

31

32

33

34

35

36

37

38

39

40

41

42

43

44

45

46 


\section{Daily stress and coping among Emergency Response Officers: a case study}

Stress is an inevitable factor in life, but coping plays an important role in modifying stress responses. Police work is one of the most stressful occupations (Strahler and Ziegert, 2015). Considering their strong responsibility toward society security maintenance, police officers are constantly under pressure, by being exposed to multiple stressors and uncertainty and they have to respond to problems, typically without sufficient warning or preparation time (Kitaeff, 2011). This is particularly more evident among Emergency Response Officers (EROs), since they are in the first line ready to respond to any emergency situation.

The ability to manage stressful events is called coping. According to Lazarus and Folkman (1984) coping is a process that involves cognitive and behavioral efforts to manage stress. According to some researchers in the area of occupational health (Anshel et al., 2013) police officers seems to have limited coping abilities. In other words, the use of ineffective coping could be explained by the highly stressful work environment, lacking in cordial professional relationships with supervisors and perceived low self-control (Anshel et al. 2013). As suggested by Anshel (2000) the ineffective use of coping by police officers may be related with the stereotypical view that any expression of stress or problems associated with the policing job might by viewed as a personal weakness.

Despite previous recommendations, police occupational health has been overlooked and several limitations have been found in previous literature. Particularly, the cross-sectional and retrospective nature of study designs, the controversy in stress and coping process definition and conceptualization and the diversity of police forces across Europe. A possible solution to overcome this gap is the use of qualitative and longitudinal methods, to capture the dynamic 
nature of stress and coping process in ecological settings (Dewe, 2001). Thus, the present study contemplated a diary methodology, based on the assumption that daily diaries give a better understanding of working behavior, since they go beyond traditional static models of human behavior, allowing for the comprehension of changing processes over time, such as stress and coping in the work contexts (Ohly et al., 2010). It is important to note that this study does not intend to replace previous methodological traditions accomplishments, but otherwise aims to provide a deep insight about the potentialities of diary methods as a complementary longitudinal and qualitative method with promising results (Clarkson and Hodgkinson, 2007) particularly among police personnel. Thus, the current diary case study aims to (1) investigate the frequency and the appraisal of daily stressors (2) determine the preferred coping strategies and, (3) ascertain its effectiveness among EROs.

occurs when the individual perceives that the demands of a situation exceed individual resources. Hence, an event will only lead to a stressful response if it is perceived as being threatening to the person, depending on the individual's subjective perception. According to this model, stress and coping is a dynamic and recursive process that includes interactions between the environment, individual appraisal and efforts to cope with the implications originated by these events. The key issue in this model is the appraisal process. According to Lazarus (1990) there are two types of appraisal: Primary appraisal that encompasses the initial evaluation of the situation, where the person gives personal meaning to events in terms of harm, threat or challenge. When an event is perceived as negative in the primary appraisal process, the individual moves to a secondary 
93 appraisal, characterized by the evaluation of the individual's ability to cope with a situation, and

94 whether or not the individual has the resources to deal with that situation. Secondary appraisal

95 interacts with the primary appraisal to determine the emotional reaction to event (Lazarus, 2000).

96 Considering that stress is an inevitable factor in life, it is coping that makes the difference

97 in adaptation processes. According to Lazarus and Folkman (1984, p.141) coping is

98 characterized by "constantly changing cognitive and behavioral efforts to manage specific

99 external and/or internal demands that are appraised as taxing or exceeding the resources of the

100 person". The most popular taxonomy of coping was proposed by Folkman and Lazarus who

101 described coping as either Problem-focused (PF) or Emotion-focused (EF). PF involves people's

102 efforts to deal with the situation (e.g., planning, information seeking or increasing efforts),

103 whereas EF involves efforts to regulate the emotional distress associated with the situation (e.g.,

104 mental withdrawal, minimizing and wishful thinking).

105 Considering that research on coping is controversial, since some investigation suggested

106 that EF coping is ineffective and increases stress but the opposite has also been described, it is

107 important to consider coping effectiveness measures (Dewe et al., 2010). According to the same

108 authors, it is important to explore both primary and secondary appraisals in particular events, in

109 order to understand why people use specific responses to stressors and whether they are in fact

110 effective.

111

112

Stress and coping among police forces

113 Police work has been identified as one of the most stressful occupations in modern

114 society (Maran et al., 2015; Shane, 2013). European security organizations in particularly have

115 been exposed to additional sources of stress, related with terrorist attacks and emigration. To face 
116 these increased demands, security organizations have to adapt quickly what may increase the

117 potential to experience added work-related stress problems. Thus, causing a detrimental impact

118 not only to the officer, but also to society (Stanley et al., 2016). Police stress has been commonly

119 categorized into two dimensions: organizational and operational (Huddleston et al., 2007; Shane,

120 2013). Organizational factors are related with bureaucracies and practices of the police

121 institution (e.g., the quasi-military nature of police institutions), and operational stressors are

122 associated with the unique nature of the work carried out by the officers while working in the

123 field (e.g., shooting episodes). There is some evidence suggesting that organizational stressors

124 are the best predictors of stress. As an example, a study conducted by Suresh et al. (2013)

125 among 220 Indian police personnel aiming to examine police stressors cross-sectionally found

126 that organizational stressors were more prevalent than task-oriented stressors. However, it is

127 important to note that in this particular study similarly to most research in this area, the role of

128 the police is not clearly specified, which leads to a problem when understanding stressors

129 typology among this population. The diversity of police forces and respective duties across

130 European police impairs comparisons between countries (Vertovec, 2007). As an example,

131 Portugal features numerous criminal police organizations, that can be classified according to

132 several criteria (e.g., administration; territorial scope, internal security system inclusion, juridical

133 nature and attributions). Previous evidence among Portuguese police forces suggests that the

134 different roles officers play, result in the experience of distinct stressors (Gonçalo et al., 2010).

135 In response to stress, police uses a variety of coping strategies. According to some

136 researchers, police personnel seem to have limited coping abilities (Anshel et al., 2013).

137 The literature is not unanimous on police coping preferences and abilities. As an example,

138 some evidence suggests that police officers show a tendency to use more PF coping (e.g., 
139 anticipated planning, dealing with problems immediately, priorities establishment) (Brown et al.,

140 1996). However, other studies found support for the use of more EF coping (e.g., talk with

141 colleagues, work more, keep things to themselves) (Alexander and Walker, 1994). Although

142 these findings are important, they fail to indicate whether coping strategies used are the ones

143 perceived to be effective.

144

\section{Current study}

The current case study sought to investigate: 1) frequency and the appraisal of daily stressors, 2) the coping strategies used to manage daily stressors, and 3) subjective evaluations of coping effectiveness among EROs. A diary research methodology was used following previous research recommendations across police science, stress and coping research (Segerstrom and Connor, 2012; van Gelderen et al., 2016). The transactional perspective of stress and coping proposed by Lazarus and Folkman was the theoretical framework underpinning the study. As a result, instead of only investigating the typology of daily stressors, stress appraisal will also be considered to provide insights on level of stressfulness experienced (Anderson et al., 2002). Furthermore, the way officers deal with stress will also be analyzed in a complementary way, by contemplating coping effectiveness (Lazarus and Folkman, 1984).

To our knowledge this is the first study investigating stress, coping and coping effectiveness among police personnel using a daily diary. By adopting this methodology, the current paper promises to impact the occupational health literature in policing by overcoming previous studies limitations. Firstly, most of previous research has been retrospective and crosssectional in nature, failing to analyze within-person daily stress fluctuations (Segerstrom and Connor, 2012). Secondly, research on stress rarely analyzes the appraisal of a situation and this 
162 information is crucial to understand stress experiences (Anderson et al., 2002; Colwell et al.,

163 2011). Thirdly, limited studies have contemplated coping effectiveness among police personnel,

164 restricting conclusions on adaptive coping for the population. Finally, most policing studies fail

165 to specify police force roles and duties involved, limiting generability of findings to other

166 countries (Kaiseler et al., 2016). Taking into considerations the particularities of the nature of the

167 police job, it is believed that the current study will provide strong practical implications for stress

168 prevention tailored for this specific population.

169

170

171

172

173

174

175

176

177

178

179

180

181

182

183

184

\section{Method}

\section{Participants and Procedure}

Fourteen EROs from the National Security Police based in Porto city in Portugal

volunteered to participate in this study. Regarding the criteria for participation, it was required that participant's role was Emergency Response Officers. All participants performed emergency police duties, since they were part of a rapid intervention team that were called to intervene in critical situations at any time. The age range was $30-45$ years $(M=35, S D=5.3)$, and they have more than 5 years of experience in policing. All police officers worked in daily 8-hour shifts.

The study was approved by the University Ethics Committee. The project was presented in a public session to the Police Commanders. Following this stage, instructions for the diary procedure were given face-to-face by the first author and police officers were asked to complete the appropriately date diary booklet at the end of each shift during 11 work days and instructed not to complete the diary on the days off work. Participants were also instructed about the confidentiality of their responses and it was explained that the diary was used only for research purposes. After completing the diary, participants returned it to the researchers. 
185 Materials

186 A simple and portable paper and pencil format (A5 sized, 11 pages) was adopted.

187 Participants were asked to note the date of completion and full researcher contact details were

188 given to all officers, who were encouraged to use these whenever they need it. The diary booklet 189 consisted of four sections: a) an open-ended stressor boxes (Levy et al., 2009) where participants 190 indicated the most stressful situation during their working day; b) a stress intensity Lickert-type 191 scale (Barnett et al., 2005) to rate their primary appraisal, by indicating how much stress they

192 felt during the indicated situation on a 5-point Lickert-type scale $(1=$ low to $5=$ high $)$; c) an 193 open-ended coping responses section, where participants wrote what they did to manage the

194 indicated stressor and d) a perceived coping effectiveness Lickert-type scale (Nicholls et al., 195 2006) to rate how effective their coping strategy was at managing the stressor on a 5-point 196 Lickert-type scale (1 = ineffective to $5=$ very effective).

197

198 Data analysis

199 A qualitative and quantitative between-person variation analysis, based on an event-based 200 approach was conducted. The analysis procedure will be explained below taking in consideration 201 the different types of data: stressors and stress appraisal, coping and coping effectiveness. These 202 analyses are similar to previous research in the area of stress and coping (e.g., Levy et al., 2009; 203 Nicholls et al., 2005; 2006; Nicholls and Polman, 2007).

204 Stressors and stress appraisal.

205 The written open-ended responses were transcribed verbatim and subjected to an 206 inductive content analysis procedure as suggested by Maykut and Morehouse (1994). The data 207 was coded into stressors categories by the first author and then verified by the other authors (e.g. 
208 Nicholls and Polman, 2007). Then, stressors categories generated for stressor responses were

209 categorized into more general dimensions labeled as Operational or Organizational Stressors as

210 recommended in the literature (e.g., Violanti and Aron, 1995). For instance, "Some citizens tried

211 to attack us" was classified as "Aggression Attempts" that was categorized as "Operational

212 Stressors". The frequency and stress appraisal was calculated considering the intensity and mean

213 intensity of each stressor. This approach is similar to previous research in the area of stress

214 appraisal (e.g. Kaiseler et al., 2009).

215 Coping and coping effectiveness.

216 Data from the open-ended coping responses section were transcribed verbatim and

217 subjected to an inductive content analysis (Maykut and Morehouse, 1994) and deductive content 218 analysis procedure (Pattton, 2002). The first phase of data analyzes was inductive. Similar 219 coping strategies were grouped together as first-order themes and assigned a descriptive label. A 220 rule of inclusion was provided for each theme. Similar first-order themes were grouped under 221 more abstract labels as second-order themes (e.g. "Increased concentration on task" was assigned 222 the rule of inclusion "refers to police officer trying to get focused on the task to cope" and was 223 coded in the second order theme of "Active coping"). The second part of data analysis involved a 224 deductive content analysis procedure. A discussion between the first and the second author was 225 performed in order to verify the appropriateness and authenticity of the second-order themes 226 (Patton, 2003). Following the modification of the coding scheme, there was 99,5\% agreement.

227 Second-order themes were then deductively classified according to the coping function that they 228 were apparently intended to serve using the dimensions PF and/or EF as recommended in the 229 literature (Lazarus and Folkman, 1984). 
In this study, we adopt the categorization of Carver et al. (1989) in the development of

231 the COPE inventory, considering that this instrument is based on the Lazarus and Folkman

232 model (Lazarus and Folkman, 1984). The COPE inventory includes 13 conceptually different

233 scales: (1) active coping: process of taking active steps to remove or circumvent the stressor or to

234 enrich its effects; (2) planning: involves thinking about how to cope with the stressor; thinking

235 about what steps to take and how to best handle the problem; (3) suppression of competing

236 activities: means putting other plans/things aside, trying to avoid becoming distracted by other

237 events; (4) restraint coping: waiting until an appropriate opportunity to act presents itself, and

238 not acting prematurely; (5) seeking social support for instrumental reasons: asking advice,

239 assistance or information in order to manage or resolve the situation; (6) seeking social support

240 for emotional reasons: getting moral support, sympathy, or understanding of others; (7) focusing

241 on and venting of emotions: tendency to focus on the aspects that distress or upset the individual

242 and to ventilate those feelings; (8) behavioral disengagement: tendency to reduce the efforts to

243 deal with the stressor, giving up of the aims with which the stressor is interfering; (9) mental

244 disengagement: assuming a wide diversity of activities that serve to distract the individual from

245 thinking about the behavioral dimension or goal with which the stressor is interfering; (10)

246 positive reinterpretation and growth: tendency to attribute a new and different meaning to the

247 distressing emotions rather than dealing with the stressor; (11) denial: refusal to believe that the

248 stressor subsists or try to act as though the stressor is not real; (12) acceptance: recognizing the

249 reality of a stressful situation, assuming that nothing could be done; (13) turning to religion:

250 tendency to turn to religion in time of stress; (Carver et al., 1989).

251 Frequencies for coping, mean coping effectiveness scores for each coping strategy used

252 and global coping effectiveness scores over the 11-day period was calculated for all the 
253 participants. To provide an indication of the effectiveness of coping strategies deployed to

254 manage the three most cited stressors, the coping effectiveness of each strategy in relation to

255 each stressor was calculated and divided by the frequency of coping themes reported for

256 managing the particular stressor. This generated a mean coping effectiveness score for each

257 coping strategy in relation to each stressor managed. To understand the effectiveness of both PF

258 and EF coping over the 11 work day period, the sample was divided into two independent groups

259 with the same size using the median point of the ranking orders (PF; EF). An independent

260 variable was created with two levels for representing the two different coping dimensions in a

261 single independent variable. Mann-Whitney $U$ test was used to compare the difference in ratings

262 of coping effectiveness (PF and EF type).

263

264

Results

From the 11 daily sheets received, a total of 146 answers were given by the police

266 officers, of which 46 referred to non-stressful events. Eight missing answers were accounted.

267 Additionally, a total of 112 stressors and 112 coping responses were reported. Results found

268 were analyzed separately based on three main categories: stressors (including stress appraisal),

269 coping and coping effectiveness.

270

271 Stressors and stress appraisal

272 Stressors reported were displayed into two general dimensions: operational (cited 88

273 times accounting for $79 \%$ of total stressors) and organizational stressors (cited 24 times

274 accounting for $21 \%$ of total stressors) (see Table 1). The three most cited stressors were public

275 disorder (32), inadequate resources (11) and vehicles chase (10). Regarding stress appraisals for 
276 the stressors cited more than five times, the three more intense stressors were gun situations $277(M=4.8)$, inadequate resources $(M=4.6)$, and public disorder $(M=3.8)$.

[TABLE 1 ABOUT HERE]

\section{Coping}

First order themes contemplated nine coping strategies; second order themes included six 281 coping responses and two coping general dimensions (PF, EF) (see Table 2). Regarding general 282 dimensions, EF coping was the most reported (cited 75 times, accounting for $67 \%$ of total coping 283 responses), followed by PF coping (cited 37 times, accounting for 33\% of total coping 284 responses). Peer support (cited 34 times) was the most reported coping strategy, followed by 285 distraction (28) and argued (24) respectively.

[TABLE 2 ABOUT HERE]

\section{Coping effectiveness}

Regarding the connections between the three most reported stressors, coping and coping 290 effectiveness, a range of different types of coping strategies were reported (see Table 3). "Peer 291 support" was used to deal with all three of the major stressors. The mean effectiveness of the 292 coping strategies varies in relation to the stressor.

\section{[ TABLE 3 IS ABOUT HERE]} 294

When analyzing a day-to-day variation in coping effectiveness it appears that PF coping 296 seems to be perceived as more effective when dealing with stressors compared with EF coping 297 (see Figure 1). The Mann-Whitney U test indicated that the use of PF coping is significantly 298 more effective for EROs $(M d=3.89)$ than EF coping $(M d=3.30), \mathrm{U}=10.00, p=.037$. 
[FIGURE 1 ABOUT HERE]

\section{Discussion}

Our findings indicate that EROs experience a variety of stressors and it appears that

304 operational stressors are the ones more commonly reported. Particularly, "gun situations" seem 305 to be appraised as most stressful. When analyzing coping EROs tend to use more EF coping, 306 particularly "peer support". However, despite variation in coping effectiveness in accordance to 307 stressor experienced, longitudinal analysis suggests that PF coping seems to be more effective. 308 Previous cross-sectional research investigating stressors typology among police officers 309 indicate that organizational stressors are the most commonly reported stressors (Suresh et al., 310 2013). However, current findings suggest that operational stressors seem to be most common 311 among EROs. This could be due to the operational nature of the work, as participants in the 312 current study were part of a rapid intervention team that mainly performed operational duties. In 313 opposition, the study by Suresh et al. (2013) does not specify the nature of officers' duties what 314 restricts conclusions when comparing findings between studies. Hence, reinforcing the need to 315 identify police forces role and responsibilities when conducting research in policing (Kaiseler et $316 a l ., 2016)$. Another alternative explanation for the different findings across studies is the novel 317 daily diary method used, which might be more sensitive to assess stress and coping in policing 318 compared with retrospective cross-sectional measures. Future research is required to confirm this 319 assumption.

320 Regarding the frequency and stress appraisal for each stressor, findings suggest that not 321 always the most frequently reported stressors were the ones perceived by EROs as most intense. 
322 As an example, although the stressor "gun situations" was not frequently reported, it seemed to

323 be appraised as severely more intense compared to frequently reported stressors. Hence, these

324 findings suggest that high stressfulness stressors should not be neglected and support the

325 argument that the frequency of a stressor is not necessarily correlated with their impact

326 (Anderson et al., 2002). Current findings highlight the need to assess stress appraisal on a daily

327 basis when aiming to understand sources of stress among EROs.

328 When analyzing the most frequently reported coping strategies used, these were EF,

329 particularly "peer support". Although EF coping was more frequently reported than PF coping,

330 the latter seems to be consistently rated as more effective. In line with these findings, Kaufmann

331 and Beehr (1989) conducted a study with 121 American PO aiming to understand buffering

332 effects of social support (EF coping) in the stressor-strain relationships. The authors found some

333 evidence of "reverse buffering", which suggests that social support interacted with job stressors

334 to increase stress intensity rather than alleviate it. Although this is not a common finding, a

335 possible explanation might be that social support may have a "negative buffering" effect

336 (LaRocco et al 1980) for officers. In other words, the support from colleagues may be negative,

337 due to lack of supportive colleagues or inefficiency of colleagues' advice to help officers deal

338 with the situation at hand. Our findings suggest that EROs may not be using EF strategies (e.g.,

339 social support) effectively (e.g., Balmer et al.,2013). However, further research is needed to

340 confirm this assumption and fully understand the "reverse buffering" effect. For this purpose, a

341 wider range of variables such as the content of communication with supportive colleagues,

342 sources of stressors and support should be analyzed.

343 In agreement with our current results emphasizing that PF coping was rated as more

344 effective than EF coping among EROs, Evans et al. (1993) suggested that police culture and 
345 training should emphasize the use of more PF coping rather than EF. Nevertheless, as proposed

346 by Balmer et al. (2013) EF coping should not necessarily be perceived as detrimental to officers'

347 wellbeing. Alternatively, PO should be trained to better regulate their emotional responses to

348 stress, in order to better deal internally (e.g., with colleagues) and externally (e.g., with civilians)

349 and meet the professional requirements. As an example, police officers are required to express

350 anger when correcting a criminal, while at the successive moment they should be able to show

351 empathy for a crime victim and it is important to highlight that police public image is created

352 based on these interactions.

Current findings add support to previous literature suggesting that coping abilities in

354 policing deserve further attention (Anshel et al., 2013). The methodology used was key to

355 understand the pattern of coping effectiveness, otherwise one could erroneously conclude that EF

356 was most effective. Future research should continue to use longitudinal designs and ecological

357 research methods to assess stress and coping in policing (Rodrigues et al., 2015). Furthermore,

358 applied practitioners and officers may find the results useful for targeted interventions. Hence,

359 considering that the work of EROs is characterized by intervening under high stressful situations,

360 where it is difficult to think clearly and consider the best coping strategy, it seems essential to

361 enhance officers' ability to cope with stressors by developing preventive tailored stress

362 management programs adapted to their needs. As an example, when stressors are operational in

363 nature, police organizations can support EROs by providing training on more oriented-action

364 solutions like motor skills and physical efficiency. Accordingly, increased fitness level in

365 policing can also foster a healthier workforce, able to better cope with chronic stress (Gerber et

366 al., 2010). Thus, this investment is likely not only to result in the welfare of EROs but may also

367 impact society safety (Maran et al., 2014). 
368 This study has some limitations. Particularly, its exploratory nature and the small sample

369 used that may restrict conclusions and generalizability of findings. However, despite the

370 limitations, the current study is pioneer in terms of specific population under study and

371 methodology used. Future research should use larger samples to test the generalization of the

372 findings. In addition, a comparison between other police forces is encouraged to fully understand

373 stress appraisals and coping mechanisms in policing, informing the design of tailored coping

374 interventions. 


\section{References}

376 Alexander, D. and Walker, L. (1994), "A study of methods used by Scottish police officers to

Anshel, M.H., Umscheid, D. and Brinthaupt, T.M. (2013), "Effect of a combined coping skills and wellness program on perceived stress and physical energy among police emergency dispatchers: An exploratory study", Journal of Police and Criminal Psychology, Vol. 28, pp. 1-14.

Balmer, G.M., Pooley, J.A. and Cohen, L. (2013), "Psychological resilience of Western Australian police officers: relationship between resilience, coping style, psychological functioning and demographics”, Police Practice and Research, Vol. 15 No.4, pp. 1-13.

Barnett, R.C., Steptoe, A. and Gareis, K.C. (2005), "Marital-role quality and stress-related psychobiological indicators", Annuals Behavioral of Medicine, Vol. 30 No. 1, pp. 36-43.

Brown, J., Cooper, C. and Kirkcaldy, B. (1996), “Occupational stress among senior police officers", British Journal of Psychology, Vol. 87, pp. 31-42.

Clarkson, G.P. and Hodgkinson, G.P. (2007), "What can occupational stress diaries achieve that questionnaires can't?", Personnel Review, Vol. 36 No. 5, pp. 684-700.

Colwell, L.H., Lyons, P.M., Bruce, A.J., Garner, R.L. and Miller, R.S. (2011), "Police officers' cognitive appraisals for traumatic events: implications for treatment and training”, Applied Psychology in Criminal Justice, Vol. 7, pp. 106-132.

Dewe, P.J. (2001), "Work stress, coping and wellbeing: Implementing strategies to better understand the relationship", in Perrewe, P.L. and Ganster, D.C. (Eds), Research in Occupational stress diaries Occupational Stress and Well Being: Exploring Theoretical Mechanisms and Perspectives, Elsevier, Amsterdam, pp. 63-96.

Dewe, P.J., O’Driscoll, M.P. and Cooper, C.L. (2010), Coping with work stress - A review and critique, Wiley-blackwell. Chichester. 
405 Evans, B. J., Coman, G. J., Stanley, R.O. and Burrows, G.D. (1993), "Police officers coping

406

407

408

409

410

411

412

413

414

415

416

417

418

419

420

421

422

423

424

425

426

427

428

429

430

431

432

433

434

435 strategies: An Australian police survey", Stress Medicine, Vol. 9, pp. 237-246.

Gerber, M., Kellmann, M., Hartmann, T. and Puhse, U. (2010), "Do exercise and fitness buffer against stress among Swiss police and emergency response service officers", Psychology of Sport and Exercise, Vol.11, pp. 286-294.

Gonçalo, H., Gomes, A., Barbosa, F. and Afonso, R. (2010), "Stresse ocupacional em forças de segurança: um estudo comparativo", Análise Psicológica, Vol. 1 No.XXVIII, pp. 165178.

Huddleston, L., Stephens, C. and Paton, D. (2007), “An evaluation of traumatic and organizational experiences on the psychological health of New Zealand police recruits" Work, Vol. 28, pp. 199-207.

Kaiseler, M., Polman, R. and Nicholls, A. (2009), "Mental toughness, stress, stress appraisal, coping and coping effectiveness in sport", Personality and Individual Differences, Vol. 47, pp. $728-733$.

Kaiseler, M., Queirós, C. and Rodrigues, S. (2016), "New approaches to compare police practice in Europe: an occupational health perspective”, in Nogala, D., Neidhardt, K., Gorgen, Th., Mesko, G., Fiquet, J.M. and Kersten J. (Ed.), European Police Science and Research Bulletin. Special Conference Issue, pp. 139-142.

Kaufmann, G.M. and Beehr, T.A. (1989), “Occupational stressors, individual strains and social supports among police officers", Human Relations, Vol. 42 No.2, pp. 185-197.

Kitaeff, J. (2011), Handbook of police psychology, Routledge Tayler \& Francis Group, New York, N.Y.

LaRocco, J.M., House, J.S. and French, J.R.P. (1980), "Social support, occupational stress, and health”. Journal of Health and Social Behavior, Vol. 21, pp. 202-218.

Lazarus, R.S. (1999), Stress and emotion: A new synthesis, Springer, New York, NY.

Lazarus, R.S. (2000), "How emotions influence performance in competitive sports", The Sport Psychologist, Vol. 14, pp. 229-252.

Lazarus, R.S. and Folkman, S. (1984), Stress, appraisal, and coping, Springer, New York, NY.

Levy, A., Nicholls, A., Marchant, D. and Polman, R. (2009), “Organizational stressors, coping and coping effectiveness: a longitudinal study with an elite coach", International Journal of Sports Science \& Coaching, Vol. 4 No. 1, pp. 31-45. 
436 Maran D.A, Varetto A., Zedda M. and Franscini, M. (2014), "Stress among Italian male and 437 female patrol police officers: a quali-quantitative survey", Policing: An International 438 Journal of Police Strategies \& Management, Vol. 37 No.4, pp. 875-890.

439 Maran, D.A., Varetto, A., Zedda, M. and Ieraci, V. (2015), "Occupational stress, anxiety and 440 441 442 443 444 445 446 447 448 449 450 451 452 453 454 455 456 457 458 459 460 461 462 463 464 coping strategies in police officers", Occupational Medicine, Vol. 65, pp. 466-473.

Maykut, P. and Morehouse, R. (1994), Beginning qualitative research: A philosophic and practical guide, Falmer Press, Philadelphia.

Nicholls, A.R., Holt, N.L., Polman, R.C. Remco, C.J.P. and Bloomfield, J. (2006), “Stressors, coping, and coping effectiveness among professional rugby union players", The Sport Psychologist, Vol. 20 No. 3, pp. 314-329.

Nicholls, A.R., Holt, N.L., Polman, R.J.C. and James, D.W.G. (2005), "Stress and coping among international adolescent golfers", Journal of Applied Sport Psychology, Vol. 17, pp. 333340.

Nicholls, A.R. and Polman, R.C.J. (2007), "Stressors, coping, and coping effectiveness among players from the England under-18 rugby union team", Journal of Sport Behavior, Vol. 30 No. 2, pp. 199-218.

Ohly, S., Sonnentag, S., Niessen, C. and Zapf, D. (2010), "Diary studies in organizational research: An introduction and some practical recommendations", Journal of Personnel Psychology, Vol. 9 No. 2, pp. 79-93.

Patton, M.Q. (2002), Qualitative research and evaluation methods, Thousand Oaks, C.A, Sage.

Rodrigues, S., Kaiseler, M. and Queirós, C. (2015), "Ecological approaches on stress assessment: A systematic review", European Psychologist, Vol. 20 No.3, pp. 204-226.

Segerstrom, S.C. and O'Connor, D.B. (2012), "Stress, health and illness: Four challenges for the future", Psychology \& Health, Vol. 27 No.2, pp. 128-140.

Shane, J. M. (2013), "Daily work experiences and police performance", Police Practice and Research, Vol. 14 No. 1, pp. 17-34.

Stanley, I.H., Hom, M.A. and Joiner, T.E. (2016), “A systematic review of suicidal thoughts and behaviors among police officers, firefighters, EMTs, and paramedics", Clinical Psychology Review, Vol. 44, pp. 25-44. 

4 6 7 8

465 Strahler, J. and Ziegert, T. (2015), "Psychobiological stress response to a simulated school

466 shooting in police officers", Psychoneuroendocrinology, Vol. 51, pp. 80-91.

467 Suresh, R.S., Anantharaman, R.N., Angusamy, A. and Ganesan, J. (2013), "Sources of job stress

468 in police work in a developing country", International Journal of Business and 469 Management, Vol. 8 No.13, pp. 102-110.

470 van Gelderen, B.R., Konijn, E.A. and Bakker, A.B. (2016), "Emotional labor among police 471 officers: a diary study relating strain, emotional labor, and service performance" 472 International Journal of Human Resource Management, pp. 1-28.

473 Vertovec, S. (2007), "Super-Diversity and its implications", Ethnic and Racial Studies, Vol. 30 $474 \quad$ No. 6, pp. 1024-1054.

475 Violanti, J.M. and Aron, F. (1995), "Police stressors: Variations in perceptions among police 476 personnel”, Journal of Criminal Justice, Vol. 23 No. 3, pp. 287-294. 


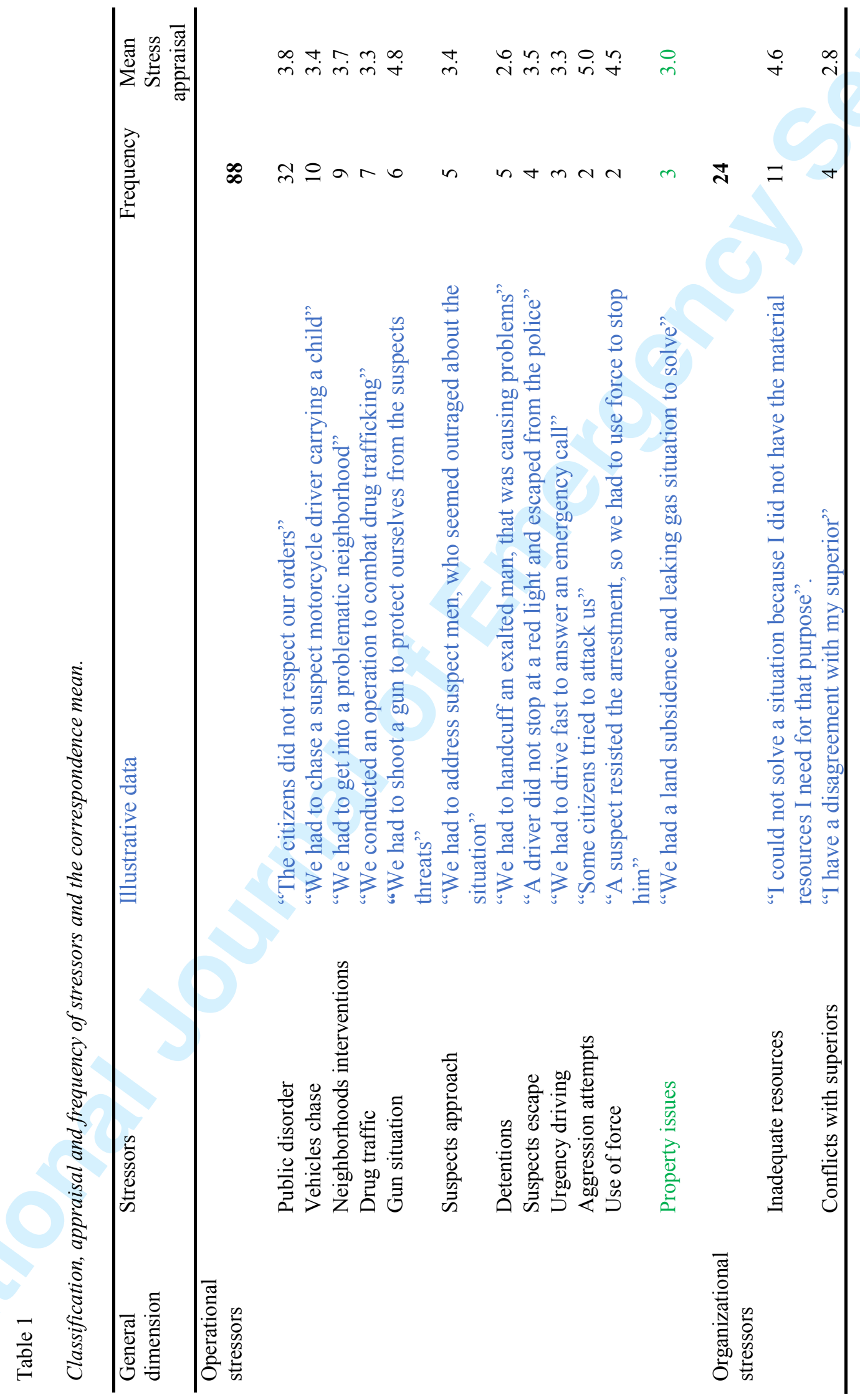

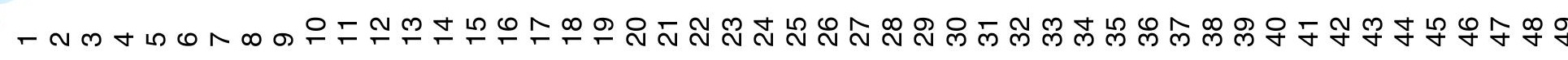




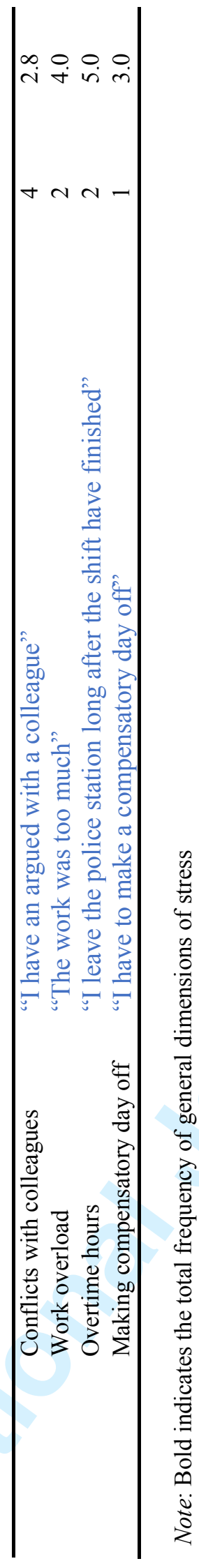

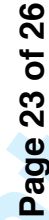




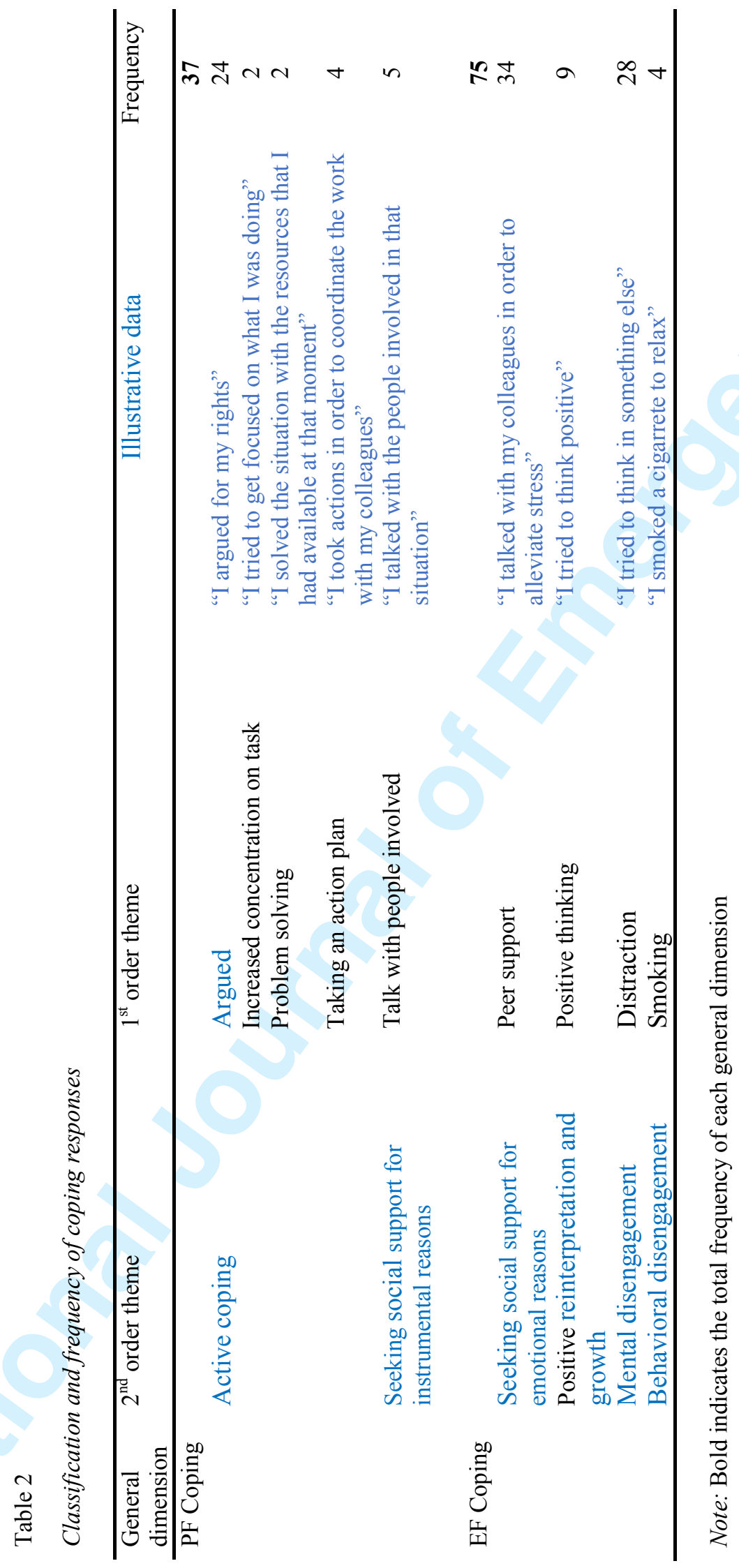

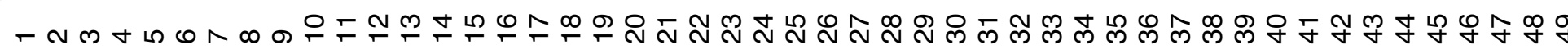




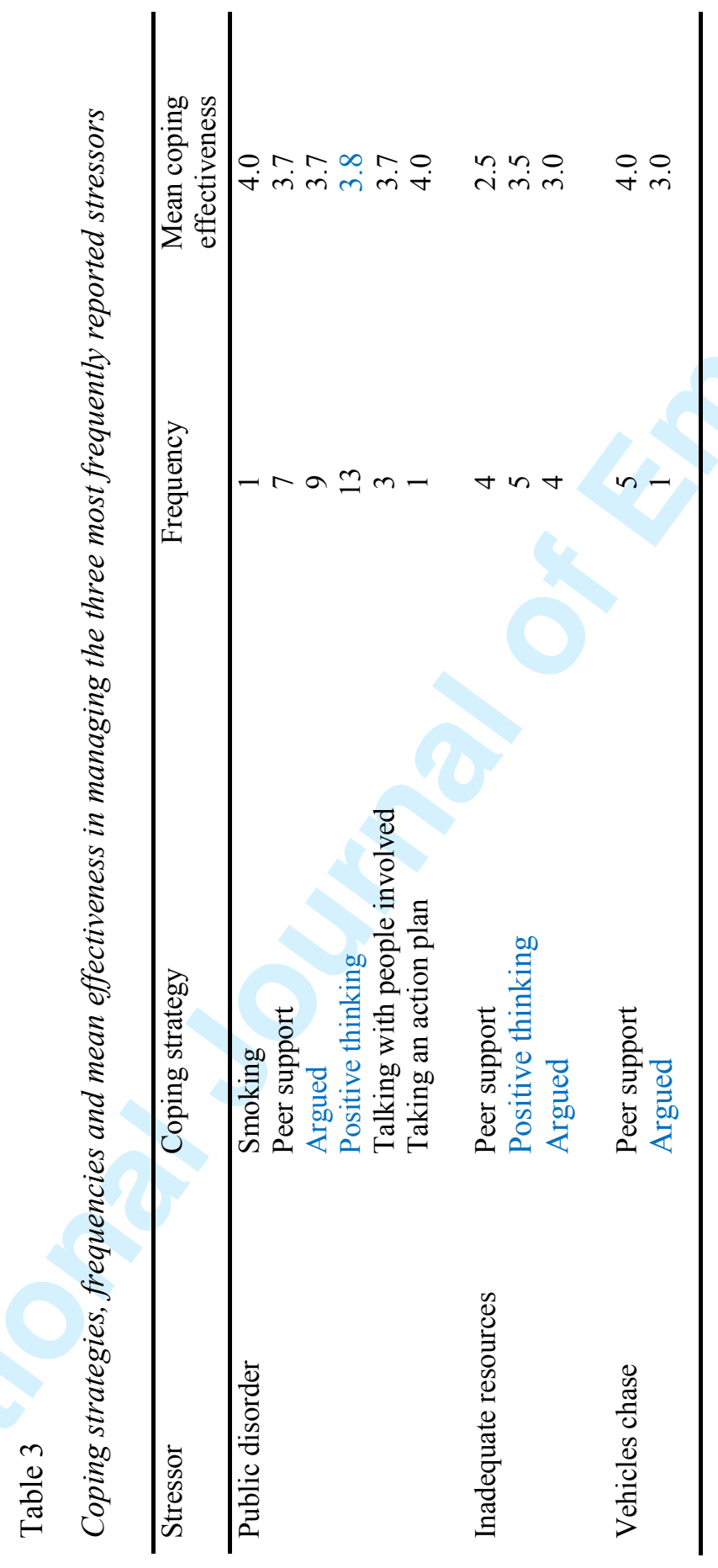

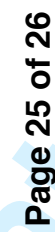




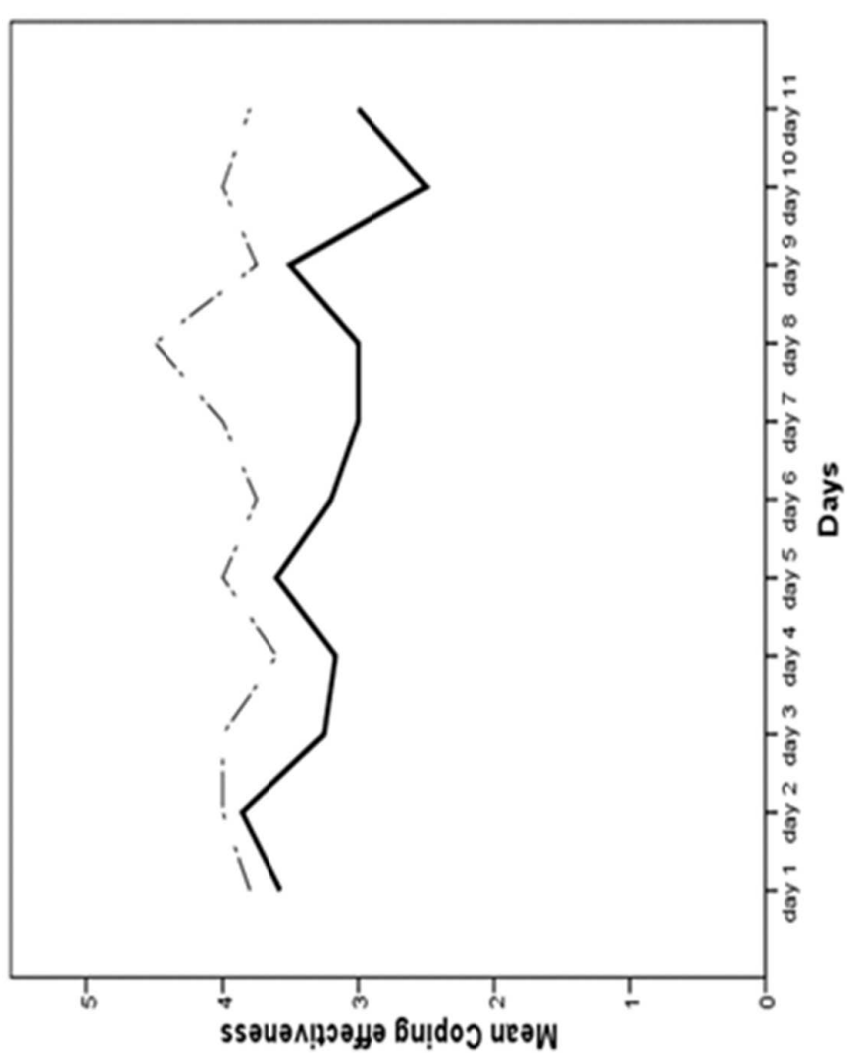

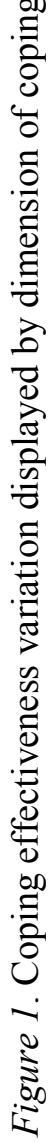

